\title{
Global environmental problems in the world
}

\author{
Galina Semenova ${ }^{1,2, *}$ \\ ${ }^{1}$ Plekhanov Russian University of Economics, Stremyanny lane, 36, Moscow, Russia \\ ${ }^{2}$ Moscow Region State University, 24, Vera Voloshina Str., Mytishchi, Moscow Region, Russia
}

\begin{abstract}
Air pollution is an environmental problem that is familiar to residents of absolutely all corners of the earth. It is especially acutely felt by residents of cities where enterprises of ferrous and non-ferrous metallurgy, energy, chemical, petrochemical, construction, pulp and paper industries operate. In some cities, the atmosphere is also severely poisoned by vehicles and boiler houses. These are all examples of anthropogenic air pollution. The subject of the study is the emissions of carbon dioxide into the environment. The purpose of the study is to solve the problem of environmental pollution by harmful substances and preserve the ecology in the world. Methodology. The main indicators characterizing the impact on the environment - $\mathrm{CO}_{2}$ emissions in the global energy sector - have been systematized; two indicators have been identified that determine the level of atmospheric pollution. Results - the scale of the influence of atmospheric air pollution on human health and the entire ecosystem as a whole was revealed.
\end{abstract}

\section{Introduction}

Continuous technological progress, the continuing enslavement of nature by man, industrialization, which has changed the Earth's surface beyond recognition, have become the causes of the global environmental crisis. Nowadays, the world's population is particularly acutely faced with such environmental problems as air pollution, ozone layer depletion, acid rain, greenhouse effect, soil pollution, pollution of the world's oceans and overpopulation.

As for the natural sources of chemical elements that pollute the atmosphere, they include forest fires, volcanic eruptions, wind erosion (dispersal of soil and rock particles), the spread of pollen, evaporation of organic compounds and natural radiation.

Every day, the average person inhales about 20,000 liters of air, which contains, in addition to vital oxygen, a whole list of harmful suspended particles and gases. Air pollutants are conventionally divided into 2 types: natural and anthropogenic. The latter ones prevail [4].

Factories emit harmful substances such as dust, oil ash, various chemical compounds, nitrogen oxides and much more. Air pollution measurements showed the catastrophic position of the atmospheric layer; polluted air is the cause of many chronic diseases.

\footnotetext{
*Corresponding author: angela-1309.m@yandex.ru
} 
What are the consequences of atmospheric pollution? Atmospheric air pollution adversely affects human health, contributing to the development of heart and lung diseases (in particular, bronchitis). Carbon dioxide in the Earth's atmosphere is at its highest level in three million years. This can lead to dramatic increases in temperature and sea levels over the centuries. For a long time, it was believed that today's levels of greenhouse gases do not exceed those of 800,000 years ago. But analysis of ice cores and oceanic sediments in the coldest place on Earth showed that 400 parts per million ( $\mathrm{ppm}$ ) were last exceeded three million years ago during the late Pliocene, when the Greenland ice sheet completely disappeared and trees grew around Antarctica.

"In the Pliocene, the global temperature was 3-4 degrees higher, and the sea level was 15-20 meters higher. But the Earth is already facing floods, droughts and storms caused by climate change. If people do not find a way to remove $\mathrm{CO}_{2}$ from the atmosphere, sooner or later, serious consequences are inevitable", Martin Siegert, a professor at Imperial College London, told reporters.

According to him, glaciologists, based on current $\mathrm{CO}_{2}$ concentrations, predict sea level rise this century from 50 centimeters to one meter.

In October 2018, the UN concluded that greenhouse gas emissions should be roughly halved over 12 years to prevent reaching the critical $1.5^{\circ} \mathrm{C}$ mark. But despite all the warnings, $\mathrm{CO}_{2}$ emissions from fossil fuels, construction, aviation and agribusiness continue to rise, and the planet could warm by $4^{\circ} \mathrm{C}$ by the end of the century.

But even if it is possible to stop global warming at the current level, the prospects remain dark. "If we stay at $400 \mathrm{ppm}$, we will still have a Pliocene climate", said isotope geochemistry professor Tina van de Flierdt.

In the same conditions as today, in the Pliocene, the Greenland ice sheet disappeared, the melting of which will raise the sea level by 7 meters. If the ice cover of West Antarctica melts, the sea level will rise by 4-5 meters.

During the Pliocene, as well as today, the Earth's poles warmed up much faster than the rest of the planet. In earlier periods, steady-state concentrations of carbon dioxide were even higher than $400 \mathrm{ppm}$, but it took millions of years to build it up. Human emissions of greenhouse gases have increased $\mathrm{CO}_{2}$ levels by more than $40 \%$ in 150 years.

\section{Materials and Methods}

For the first time in human history, the concentration of carbon dioxide in the Earth's atmosphere reached $415.26 \mathrm{ppm}$ (parts per million). The record pollution was reported by scientists at the Scripps Institute of Oceanography in San Diego. The average growth rate of $\mathrm{CO}_{2}$ concentration remains high. Compared to the 2019 level, the increase will probably be around three parts per million, up from an average increase of $2.5 \mathrm{ppm}$ in previous years. "Probably the result of a moderate El Niño impact that overlaps with the effects of fossil fuel burning", said Ralph Keeling, director of monitoring at Scripps.

For comparison, in 2015, the level of carbon dioxide in the atmosphere was $400 \mathrm{ppm}$, and at the end of 2018, the average annual concentration rose to $405.5 \mathrm{ppm}$. Scientists suggest that if the level of carbon dioxide increases at a similar rate, then by the beginning of the new century, the concentration of carbon dioxide will reach $1200-1300 \mathrm{ppm}$. As a result, global warming will intensify, the temperature of the water in the oceans will rise by eight degrees, which will cause a large-scale ecological disaster [2].

There is an incredible amount of air pollutants, and ecologists are constantly discovering new ones, which is associated with the rapid pace of industrial development and the introduction of new production and processing technologies.

The main types of pollutants are: 
- carbon monoxide. Chemical formula - CO. It is a colorless and odorless gas. It appears after incomplete combustion of coal, gas, oil and other fuels under conditions of insufficient oxygen and low temperatures. It interacts with the hemoglobin present in the human blood and blocks the flow of oxygen into it. It was first determined in 1776 by the physician Jacques de Lasson;

- carbon dioxide. Chemical formula - $\mathrm{CO}_{2}$. Colorless gas, but with a sour smell and taste. Appears after complete oxidation of carbon. It is one of the greenhouse gases;

- sulfur dioxide. Chemical formula - $\mathrm{SO}_{2}$. Colorless gas. The smell is pungent. It appears when burning such fuels that contain sulfur and when processing sulfur ores. One of the types of gas that forms acid rain. In the human body, it first causes a loss of taste, then shortness of breath, pulmonary edema and respiratory arrest;

- nitrogen oxides and dioxides. Chemical formula - $\mathrm{NO}$ and $\mathrm{NO}_{2}$, respectively. Appears during any combustion processes. Its amount depends on the combustion temperature. The higher the temperature is, the more it is. The sources of its appearance are enterprises for the production of nitrogen fertilizers and acids, nitrates, anilic acid, vehicles, industrial enterprises and some types of household equipment.

- ozone. Chemical formula - $\mathrm{O}_{3}$. Gas with a characteristic odor. Most toxic of all pollutants;

- hydrocarbons. Some of the most common with various variants of carbon $\mathrm{C}$ and hydrogen $\mathrm{H}$ compounds. They are found in unburned petroleum products, liquids for dry cleaning, solvents and much more;

- lead. Chemical sign - Pb. Silver-gray metal, toxic in any form. It is used in the production of ammunition, paints, car batteries, and etc. Its main source of release into the atmosphere is the exhaust gases of vehicles with engines powered by leaded gasoline;

- industrial dust. It is usually subdivided into classes depending on the origin.

Mechanical dust appears in the technological processes of grinding substances and materials. Sublimates are formed during condensation of refrigerated gas vapors and passed through technological equipment. Fly ash is suspended in the flue gas and represents the unburned mineral impurities of the fuel. Industrial soot or solid highly dispersed carbon is formed by incomplete combustion of hydrocarbons or their thermal decomposition [1].

These substances pollute the air basin most frequently. But this is only a small part of them, the atmosphere contains a lot of various compounds, and some of them are even unknown to scientists. Basically, the current sources of pollution are thermal power plants operating on solid fuels and coal.

According to the International Energy Agency (IEA), the global volume of carbon dioxide emissions into the atmosphere at the end of 2019 amounted to 33 billion tons. Thus, it remained at the same level as in 2018 , despite the growth of the world economy by $2.9 \%$ [4].

For example, in the United States, the level of harmful emissions decreased by 140 million tons, or $2.9 \%$. In the European Union, their volume fell by 160 million tons, which is equivalent to $5 \%$, and in Japan - by 45 million tons (-4\%). However, developing economies and third world countries did not support this trend - their total carbon dioxide emissions increased from 21.6 billion to 22 billion tons [3].

In Russia, the value of the maximum permissible values of harmful substances in the air are shown in table 1 . 
Table 1. Maximum permissible values of harmful substances in the air.

\begin{tabular}{|l|c|c|}
\hline \multicolumn{1}{|c|}{ Name of substance } & $\begin{array}{c}\text { Maximum admissible one-time } \\
\text { value, } \mathbf{~ m g} / \mathbf{m}^{\mathbf{3}}\end{array}$ & $\begin{array}{c}\text { Average daily allowable value } \\
\mathbf{m g} / \mathbf{m}^{\mathbf{3}}\end{array}$ \\
\hline Sulphur dioxide & 0.5 & 0.05 \\
\hline Phosphoric anhydride & 0.15 & 0.05 \\
\hline Nitrobenzene & 0.008 & 0.008 \\
\hline Carbon monoxide & 3.0 & 1.0 \\
\hline Sulfuric acid vapors & 0.3 & 0.1 \\
\hline Ammonia & 0.2 & 0.04 \\
\hline Naphthalene & 0.003 & 0.003 \\
\hline
\end{tabular}

The standards are constantly being supplemented, and new ones are being developed. The ecological situation in our country is determined by two factors: a decrease in expenses for environmental protection, on the one hand, and a smaller scale of economic activity than before, on the other.

For example, in 2000, there were almost 21 thousand enterprises in Russia, which have emissions into the atmosphere. These emissions (including cars) amounted to more than 85 million tons, of which almost 16 million - without any treatment. For comparison, in the USSR in the mid-80s, emissions from stationary sources and road transport were 95 million tons, in Russia in the early 90s - about 60 million tons [4].

Figure 1 shows $\mathrm{CO}_{2}$ emissions in the global energy sector.

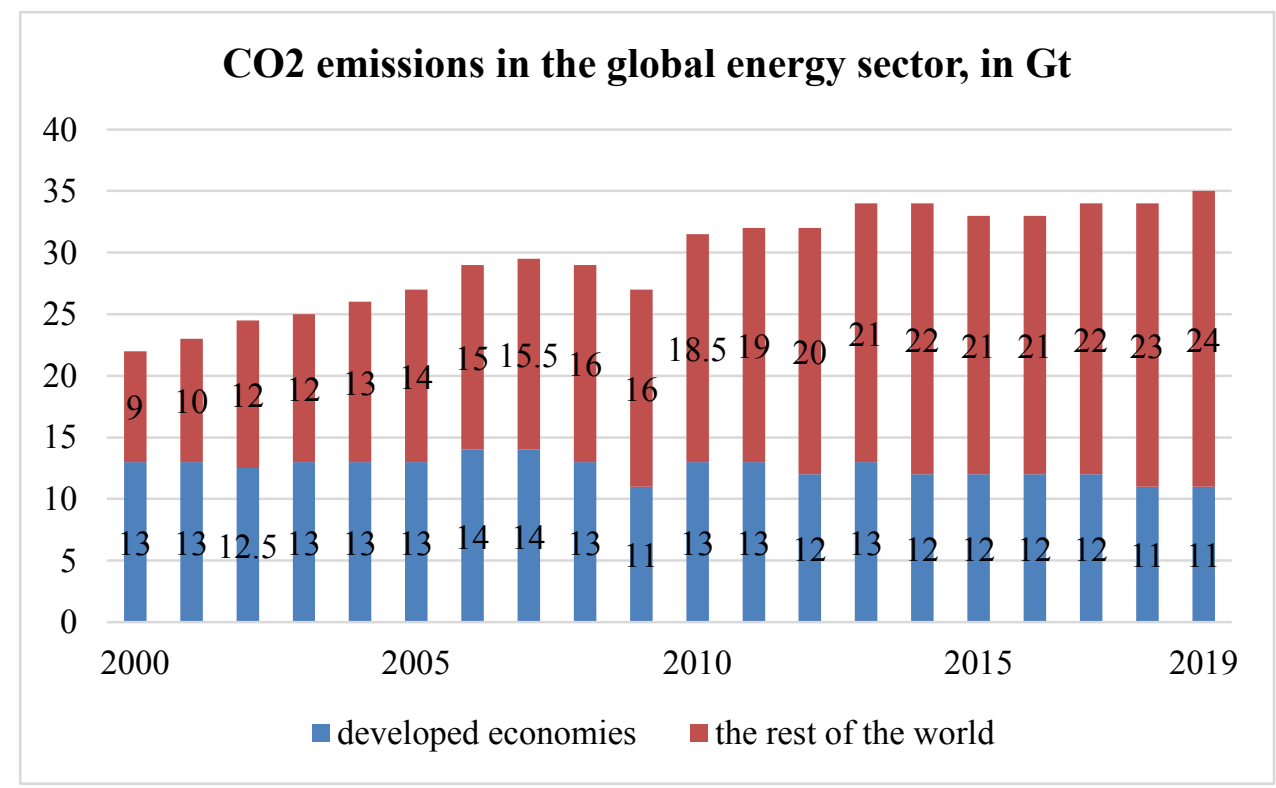

Fig. 1. $\mathrm{CO}_{2}$ emissions in the global energy sector, in Gt.

$\mathrm{CO}_{2}$ emissions stopped rising for the first time in three years, remaining at 33.3 gigatons (Gt) in 2019, according to the IEA. At the same time, the world economy last year grew by $2.9 \%$. "We must now work hard to make 2019 go down in history as the year when global emissions peaked, rather than just another pause in their growth", said Executive Director of the IEA Fatih Birol.

The country where $\mathrm{CO}_{2}$ emissions fell the most was the United States, which President Donald Trump pulled out of the Paris Climate Agreement, by 140 million tons, or $2.9 \%$. Now they are $4.8 \mathrm{Gt}$, which is almost $1 \mathrm{Gt}$ less than the peak in 2000. This was made possible by a $15 \%$ reduction in coal use in power generation last year. Despite Trump's 
support, the coal industry is finding it increasingly difficult to compete with natural gas, which prices have dropped dramatically due to the shale revolution. If in 2008 the price of natural gas in the United States almost reached $\$ 14$ per 1 million British thermal units (BTU), then since 2012 it has not exceeded \$4, with the exception of several short-term periods. Last year, gas cost \$2-3, and this year the price fell below \$2 per 1 million BTU, including due to the reduction in electricity demand as a result of cool summers and mild winters [2].

In the European Union, emissions decreased by 160 million tons, or 5\%, to $2.9 \mathrm{Gt}$. For the first time in the region, the share of gas in electricity generation exceeded the share of coal, the IEA notes. And wind power, which has already become a profitable sector even without government subsidies, has almost caught up with the coal industry. In Japan, emissions decreased by 45 million tons, or $4.3 \%$, to $1.03 \mathrm{Gt}$, because the country is resuming operation of nuclear reactors, which stopped working after the accident at the nuclear power plant in Fukushima in 2011 [2].

The liquefied natural gas industry in Qatar will capture and reduce emissions of more than 5 million tons of $\mathrm{CO}_{2}$ per year by 2025. According to climatologists, methane is responsible for about a quarter of global warming that has occurred since then. In general, according to the IEA, energy-related in developed countries emissions fell to the level of the late 1980s, although the demand for electricity was three times lower at that time. However, in the rest of the countries, emissions increased by almost 400 million tons in 2019. Almost $80 \%$ of this increase was in Asia, where demand for coal continues to increase. According to IHS Markit, it accounts for $27 \%$ of the world's energy consumption today.

Russia is one of the four countries that most emit carbon dioxide into the atmosphere as a result of fuel combustion. However, it turns out that Russia is not such an energy inefficient country and not such an air-polluting country [5].

China is in the first place in $\mathrm{CO}_{2}$ emissions in the world, accounting for almost a quarter of all emissions. For the period from 1992 to 2010, this figure increased by $240 \%$.

The USA is the second most emitting country. And emissions in America have fallen since 2008, when the crisis has broken out. And this once again shows how much the issue of air pollution is directly related to economic success.

India is one of the three countries with largest carbon dioxide emissions. However, India does not want to reduce $\mathrm{CO}_{2}$ emissions, on the contrary, it is going to increase the use of coal, which will lead to an increase in the emission of such gases.

Japan has set a goal to reduce greenhouse gas emissions by $26 \%$ by 2030 compared to 2013. As Japanese Prime Minister Shinzo Abe explained, this goal will be supported by the necessary measures and technologies. The energy balance is planned to be brought to the following indicators: $22-24 \%$ - renewable energy sources, $20-22 \%$ - nuclear power plants, the rest - oil, gas and coal.

By 2030, German industry is expected to cut $\mathrm{CO}_{2}$ emissions by one fifth. The energy sector, in turn, will cut emissions in half. In 2018, the government will assess the impact of following the plan on the economy, society and the labor market. The authorities stressed that the goals may change after the revaluation.

Note that Russia in 1990-2009 reduced carbon dioxide emissions into the atmosphere by almost a third, but, alas, not because of the increase in energy efficiency, but because many enterprises simply closed during the economic collapse of the 90s. According to the IEA forecast, we will reach the level of emissions equal to $75 \%$, as it was in 1990 , only in 2035. In most of the former Soviet republics and countries of the Socialist Bloc, emissions decreased by $50-60 \%$ [3].

The scale of the impact of air pollution on human health and the entire ecosystem as a whole is simply enormous, and many people underestimate them. 
Firstly, due to polluted air, the greenhouse effect has developed, which gradually, but globally, changes the climate, leads to warming and melting of glaciers, provokes natural disasters. It can be said that it leads to irreversible consequences in the state of the environment.

Secondly, acid rain is becoming more frequent, which has a negative impact on all life on Earth. They are responsible for the death of entire fish populations that are unable to live in such an acidic environment. A negative impact is observed when examining historical monuments and architectural monuments.

Thirdly, fauna and flora suffer, since dangerous vapors are inhaled by animals, they also enter plants and gradually destroy them. A polluted atmosphere has an extremely negative effect on human health. The emissions enter the lungs and cause malfunctions in the respiratory system, severe allergic reactions. Together with the blood, dangerous compounds are carried throughout the body and wear it out a lot. And some elements are capable of provoking cell mutation and degeneration [6-9].

There are 3 levels of air pollution monitoring [1]:

- Impact-constantly carried out operational control. The analysis is carried out on the basis of the results of indicators of sensors showing changes in the level of air pollution per day.

- Regional - tracking changes in each contour region of the country.

- Global - control over air pollution throughout the country and the world as a whole.

Every year, all countries check how much their air is clean and its composition. For these purposes, it is customary to use two indicators:

1. IAP - index of air pollution. To determine it, it is necessary to know the average annual concentration of the toxin and the MPC of the substance during the day and the toxicity coefficient of the compound.

\section{$M P C=$ indicator of the maximum value /indicator of the maximum permissible concentration of a substance in the atmosphere}

IAP is assessed on a 14-point scale. Where 5 is the low level, 14 is the maximum allowable rate.

2. SI - standard index of pollution. Estimated as a percentage: $20 \%$ - high pollution, $40 \%$ - extremely high pollution.

According to the World Health Organization (WHO), the financial loss due to air pollution in Europe is about 1.6 trillion US dollars. This is the result of about 600,000 premature deaths (about $\$ 1.4$ trillion) and diseases (about $\$ 200$ billion). Therefore, it is necessary to invest in technologies that will achieve "carbon neutrality", when greenhouse gas emissions generally do not increase [5].

\section{Discussion}

According to Vitor Gaspar, Director of the IMF's Fiscal Affairs Department, "Moving from existing fuel prices to effective prices at the global level would reduce the death rate associated with air pollution from fossil fuel combustion by $63 \%$, mainly by reducing mortality from burning coal, reduce energy-related carbon emissions by $23 \%$ and generate revenues equivalent to $2.6 \%$ of GDP".

The IEA explains the reduction in emissions in countries with advanced economies "due to the growing role of renewable energy sources, the shify away from coal and natural gas as fuel and the growth of nuclear power supply". "Now we must make efforts to make 2019 remembered as the last peak in greenhouse gas emissions in the world, and not another pause in its growth," said the head of the IEA Fatih Birol. "We have energy technologies to achieve this, and we must take advantage of all of them". 
Simon Retallack, director of the Carbon Trust, called the news of the halt in global emissions growth a sign of "real progress" in the fight against climate change. But to prevent this success from being temporary, developed and developing countries must move faster to cleaner energy, he said. "They also have to make sure that emissions in other sectors, in particular in transport and agriculture, stop growing and begin to decrease", said Simon Retallack.

\section{Conclusions}

The problem of atmospheric air pollution is very relevant, especially when you consider that the ecology has greatly deteriorated over the past few decades. It needs to be solved in a comprehensive manner and in several ways. Effective measures are proposed for the prevention of atmospheric air pollution:

- to combat air pollution at individual enterprises, it is imperative to install treatment and filtering facilities and systems. And at especially large industrial plants, it is necessary to start introducing stationary posts for monitoring air pollution;

- to avoid air pollution from cars, it is necessary to switch to alternative and less harmful energy sources, for example, solar panels or electricity;

- replacing combustible fuels with more accessible and less hazardous ones, such as water, wind, sunlight and others that do not require combustion, will help to protect the atmospheric air from pollution;

- protection of atmospheric air from pollution must be maintained at the state level, and there are already laws aimed at protecting it.

One of the effective ways that air protection from pollution should include is the establishment of a system for the disposal of all waste or their recycling. Plants should also be used to tackle air pollution. Landscaping will improve the atmosphere and increase the amount of oxygen in it. Knowing the essence of the problem of air pollution, its relevance and the main solutions, it is necessary to jointly and comprehensively fight pollution by the whole world.

\section{References}

1. R.A. Burko, T.V. Tereshina, Young scientist 11(58), 237-238 (2013) https://moluch.ru/archive/58/8206/

2. Nevelsky, M. Overchenko, Global carbon dioxide emissions stopped growing in, Vedomosti HR 17.02.2020 (2019)

3. G. Semenova, E3S Web of Conferences 157, 02023 https://doi.org/10.1051/e3sconf/202015702023

4. Vatin, N.I., Chechevichkin, V.N., Chechevichkin, A.V., Shilova, Y.S. Possible applications of clinoptilolites for natural water purification. Magazine of Civil Engineering. 2013. 37(2). DOI:10.5862/MCE.37.12.

5. Vatin, N.I., Chechevichkin, V.N., Chechevichkin, A.V., Shilova, Y., Yakunin, L.A. Application of natural zeolites for aquatic and air medium purification. Applied Mechanics and Materials. 2014. 587-589. Pp. 565-572. DOI:10.4028/www.scientific.net/AMM.587-589.565.

6. Vatin, N.I., Chechevichkin, V.N., Chechevichkin, A.V., Shilova, Y.S. Possible applications of clinoptilolites for natural water purification. Magazine of Civil Engineering. 2013. 37(2). DOI:10.5862/MCE.37.12. 
7. G. Semenova, E3S Web of Conferences 91, 08046 (2019) https://doi.org/10.1051/e3sconf/20199108046

8. The Russian Union of Industrialists and Entrepreneurs of Russia, http://xn-olaabe.xn--p1ai/

9. N. Tulebayeva, D. Yergobek, G. Pestunova, A. Mottaeva, Z. Sapakova, E3S Web of Conferences 159, 01012 (2020) https://doi.org/10.1051/e3sconf/202015901012

10. T. Gorokhova, et al. E3S Web of Conferences 135, 04069 (2019) doi:10.1051/e3sconf/201913504069 